Article

\title{
Estimating the Impact of Air Pollution on Inbound Tourism in China: An Analysis Based on Regression Discontinuity Design
}

\author{
Daxin Dong ${ }^{\circledR}$, Xiaowei Xu * and Yat Fung Wong ${ }^{\circledR}$ \\ School of Business Administration, Southwestern University of Finance and Economics, Chengdu 611130, China; \\ dongdaxinedu@126.com (D.D.); hyf@swufe.edu.cn (Y.F.W.) \\ * Correspondence: xiaoweix@swufe.edu.cn
}

Received: 6 March 2019; Accepted: 15 March 2019; Published: 20 March 2019

check for updates

\begin{abstract}
Prior studies have suggested the existence of a reverse causality relationship between air quality and tourism development: while air quality influences tourism, dynamic segments of the tourism industry (e.g., cruising, airline, foodservice) have impacts on air quality. This reverse causality hinders a precise estimate on the effect of air pollution on tourism development within a conventional econometric framework, since the variable of air pollution is endogenous. This study estimates the impact of air pollution on the inbound tourism industry in China, by controlling for endogeneity based on a regression discontinuity design (RDD). The estimate is derived from a quasi-experiment generated by China's Huai River Policy, which subsidizes coal for winter heating in northern Chinese cities. By analyzing data from 274 Chinese cities during the period 2009-2012, it is found that air pollution significantly reduces the international inbound tourism: an increase of $\mathrm{PM}_{10}$ (particulate matter smaller than $10 \mu \mathrm{m}$ ) by $0.1 \mathrm{mg} / \mathrm{m}^{3}$ will cause a decline in the tourism receipts-to-local gross domestic product (GDP) ratio by 0.45 percentage points. This study also highlights the importance of controlling for endogeneity, since the detrimental impact of air pollution would otherwise be considerably underestimated. This study further demonstrates that, although air pollution is positively correlated with the average expenditure of each tourist, it substantially depresses the number of inbound tourists. The results imply that air quality could potentially influence inbound tourists' city destination choices. However, it is interesting to note that travelers in air polluted cities in China tend to spend more money.
\end{abstract}

Keywords: air pollution; inbound tourism; China, $\mathrm{PM}_{10}$; regression discontinuity design

\section{Introduction}

Sustainability is rooted in environmentalism, and it has been regarded as a fundamental concept for tourism development [1]. A balance among environmental, economic, and social sustainability, the three main pillars of sustainability, is the key to achieving sustainable tourism development [2]. Since tourism has become one of the largest-growing economic sectors in the world, policy makers should shift their focus from the quantity of economic growth to the quality of growth, which could be determined by natural environmental performance. The impact of environmental factors (e.g., nice weather, personal safety, unpolluted environment, standards of hygiene of the destination) on the tourism industry cannot be overlooked, as they influence customers' destination choices [3,4], travel experiences [5], as well as tourist aesthetic judgement [6]. Moreover, pollution becomes a major health concern. For instance, 4.2 million deaths every year are linked to outdoor air pollution exposure [7]. However, it is noticed that the impact of environmental quality on tourism development has been examined less extensively than the impact of tourism on environmental quality. 
Since 2014, air quality improvement has been regarded as a top priority for sustainable development by the United Nations Environment Assembly [8]. According to AirVisual [9], the top 10 polluted cities were dominated by India, Pakistan and China in 2018. It was reported that India's toxic air caused 1.24 million deaths in 2017 [10], and prompted visitors to defer or cancel their trips to destinations such as Delhi, Agra and Varanasi [11]. In Pakistan, air pollution led to an increase in asthma and other respiratory diseases [12]. China's problems with severe air pollution have also received worldwide attention in recent years. Haze, a serious health threat, has become one of the most disastrous weather events in China [13]. According to the Wall Street Journal [14], foreign visitors to Beijing, China suddenly declined by roughly $50 \%$ in the first three quarters of 2013. One of the main factors for the decline might be the city's notorious air pollution, as hyped by foreign media, which increases foreign visitors' perceptions of environmental risks in China.

Although the number of tourists inbound for China in 2017 reached 139 million, this only represented a $0.8 \%$ increase compared to last year. Dai Bin, the president of the China Tourism Academy, regarded environmental concerns as being one of the potential reasons for deterring international tourists [15]. It is implied that inbound tourism in China should be improved by adhering to the overarching goal of achieving sustainable tourism development. To provide additional evidence on the negative impact that air quality might have on inbound tourism in China, quantitative analyses are needed.

With the aim of providing a more precise estimation on the effects of air pollution, this study carefully considers the following points: (1) the development of tourism might, reversely, affect environmental quality. This is confirmed by some existing studies that have discussed the influence of the tourism industry on pollution. The existence of reverse causality hinders a precise estimate on the effect of air pollution on tourism development within a conventional econometric framework, as air pollution is an endogenous variable. This issue should be dealt with in econometric regressions. (2) This study takes into account the effect of China's Huai River Policy, which subsidizes coal for winter heating to people living in northern Chinese cities. Given that this policy has led to a dramatically higher degree of air pollution in northern China than that in southern China [16], a discontinuous distribution of air pollution around the north-south boundary could be observed. In this situation, regression discontinuity design (RDD) is regarded as a powerful method for dealing with the endogeneity of the air pollution variable, while identifying a causal effect from air quality to tourism development. (3) Given that the distribution of tourism resources is highly uneven in different districts in China, the representativeness of the sample used in analysis should be noted. Existing studies in literature have either investigated the circumstances at aggregate levels such as country- and province-levels, or have focused on some hot tourism destinations such as Beijing and Shanghai. If the study subject is the whole country or the provinces, the findings may be driven by circumstances in districts with large tourism scales. If only the hot tourism destination cities are considered, many cities would be ignored, even though they probably have distinct characteristics. Differently, this study analyzes China's city-level data instead of its national- or province-level data. Our sample consists of 274 cities, covering over $80 \%$ of the districts of China. (4) This study inspects the impacts of air quality on three tourism indicators: inbound tourism receipts, the number of arrivals, and the expenditure per tourist. These three variables are all crucial indicators in tourism analysis. This study attempts to provide a comprehensive understanding on how air quality influences the tourism industry.

This study contributes to the body of literature in two aspects. First, since this study addresses explicitly the endogeneity issue in the regressions, it probably provides a more accurate estimate on the damage of air pollution on China' inbound tourism. According to the estimates of this study, if $\mathrm{PM}_{10}$ (particulate matter smaller than $10 \mu \mathrm{m}$ ) density increases by $0.1 \mathrm{mg} / \mathrm{m}^{3}$, the tourism receipts-to-local gross domestic product (GDP) ratio will decline by 0.45 percentage points, implying a reduction of 567 million RMB (approximately 80 million USD) in tourism receipts; the tourist arrivals-to-local population ratio will reduce by 4.6 percentage points, implying a reduction of 0.19 million tourists. The estimates of this study demonstrate that pollution's negative impact will 
be substantially underestimated if the endogeneity is not mitigated. Second, this study is the first attempt to analyze the impact of air pollution on tourism over a wide sample of Chinese cities. The sample covers 274 cities, containing over $80 \%$ of Chinese cities. This sample includes not only a set of well-known cities with high levels of tourism development, but also many promising cities which currently have medium or small scales of tourism industries. Therefore, the empirical findings of this study reflect the general situations in China.

The rest of this paper is organized as follows. Section 2 presents a literature review on the interaction between air pollution and tourism. Section 3 illustrates the significant discontinuity of air pollution and tourism variables around the north-south boundary of China. Section 4 demonstrates the empirical model and the data used in the regressions. The estimate results are discussed in Section 5. Discussions are then presented in Section 6. Finally, Section 7 provides the conclusions, limitations of this study, and recommendations for future research.

\section{Literature Review}

This literature review section examines the bilateral causality between environmental quality and tourism development, with a special focus on air pollution issues.

\subsection{The Relationship between Environment and Tourism}

Numerous studies have investigated the impact of tourism growth on local economic development $[17,18]$. It has been acknowledged that tourism, especially in less developed countries, is regarded as a generator of economic benefits including improvements in employment, incomes and exports $[19,20]$. Since tourism development depends greatly on climatic and natural resources such as rivers, lakes, and landscape [21], tourism industry practitioners should optimize the use of the environmental resources to promote economic growth and alleviate poverty.

In recent decades, tourism was no longer a luxury good, but widely enjoyed by the general public. It is noticed that individuals' perceptions of tourism-environment relationship have changed due to tourism's potential impact on the natural environment such as noise pollution, water pollution, air pollution, biodiversity loss and coastal degradation [22-24]. The multiple segments of the tourism industry could also induce negative environmental impacts. For instance, tourism transport cruise ship emission could cause air pollution [25], and the hotel sector increases environmental burden due to its high level of energy and water consumption [26]. A recent report indicates that worldwide tourism industry accounts for $8 \%$ of global $\mathrm{CO}_{2}$ emissions from 2009 to 2013 [27]. Increasing attention has been paid to the appropriate handling of the relationship between tourism and the environment rather than speeding up the tourism resources' exploitation and utilization.

In addition to the aforementioned studies highlighting the tourism-influenced environmental disturbances, a number of studies have indicated the impact of environment on tourism industry, especially for international tourism [28]. The rationale behind is that changes in climate or weather conditions could influence the demand for tourism. Poor environmental conditions in the destination country could reduce inbound travelers' visit intentions, while poor environmental conditions in the place of origin could serve as a push motivator for outbound travelers [29].

\subsection{The Impact of Air Pollution on Tourism}

Air pollution not only harms the health of tourists, but also reduces air visibility, which directly influences tourists' travel experiences. Therefore, good air quality is indispensable for tourism sustainability. As an increasing number of people are now aware of daily levels of air pollution, scholars have started to investigate the impact of air pollution on tourism, and they have found that haze-related air pollution significantly reduces a country's inbound tourism [30]. In recent years, China has been suffering from a serious air pollution problem, which has received worldwide attention since 2013. Beijing, the capital of China, once reached a $\mathrm{PM}_{2.5}$ (particulate matter smaller than $2.5 \mu \mathrm{m}$ ) concentration value that was around 40 times the World Health Organization's maximum 
guideline [31]. Tourists' perceptions of haze pollution alter the tourism seasonality in Beijing [4]. Since then, China's air pollution issues have become the focus of some studies examining the relationship between air pollution and tourism.

From a micro-level perspective, Becken et al. [32] conducted a survey on US and Australian residents, and found that their perceived air quality risk in China has a significant negative impact on destination image and visit intention. Similarly, Peng and Xiao [33] examined the impact of smog in the air on the domestic travel demand to Beijing, and found a significant indirect impact of travel risk perception on avoidance tendency, mediated by travel dissatisfaction and negative destination image.

Evidence on the negative impacts of air pollution on tourism have also been found from macro-level analyses. Deng et al. [34] report that industrial waste gas emissions in provinces of China have a significant negative effect, both directly on the local inbound tourism industry, and indirectly via a spillover effect on other provinces. Using Google Trends search results, $\mathrm{Xu}$ and Reed [35] reported that the people's high degree of concerns about the pollution in China resulted in lower inbound tourism. In a study for 24 Chinese cities, Zhou et al. [36] reported that if the value of the air pollution index increased by $1 \%$ over the last month, the number of inbound tourist arrivals in the current month would decline by $0.25 \%$. Other researchers have reported similar findings, with a focus on one specific city or scenic spot in China, including the Sun Moon Lake Scenic Area in Taiwan [37] and Shanghai [38].

These aforementioned studies all support the claim that air pollution harms tourism development. However, it is noticed that previous studies failed to take into account the endogeneity of air pollution resulting from reverse causality, which might result in either an overestimation or an underestimation of the results. More specifically, in the case that the development of the tourism industry mitigates air pollution, an OLS (Ordinary Least Squares) estimate with tourism development as the dependent variable and pollution as the explanatory variable, may report a spurious negative coefficient. This causes an overestimate on the effect of air pollution. On the contrary, in the case that tourism development increases pollution emissions, an OLS estimate on the air pollution's impact tends to underrate the real magnitude. The previous literature indicates that these two different circumstances are both possible.

\subsection{The Impact of Tourism on Air Pollution}

Tourism, often referred to as the non-smoking industry, has now posed potential threats to natural resources in the world. Belsoy et al. [39] summarized that the negative environmental impacts of tourism include the disruption of ecological life systems, air, water and noise pollution, and pressure on land resources. According to a recent study on the carbon footprint of global tourism, the tourism industry is responsible for $8 \%$ of global greenhouse gas emissions [27]. Several scholars also reported that tourism expansion exacerbates pollution. For instance, Azam et al. [40] reported a positive effect from tourists' arrivals on $\mathrm{CO}_{2}$ emission in Malaysia. Similar findings are reported for some other countries, including Turkey [41], Cyprus [42], and 35 Organization for Economic Co-operation and Development (OECD) countries [43]. Lu et al. [44] found that the growth of domestic tourism earnings in Qingyang City, Gansu, China increases the local discharge of garbage; and air pollutants discharged from waste disposal have become an air pollution source [45]. Based on a study in the Mallorca area of Spain, Saenz-de Miera and Rosselló [24] found that a 1\% increase in tourist numbers was related to a $0.45 \%$ increase in $\mathrm{PM}_{10}$ concentration levels.

Meanwhile, there were actually some contradictory findings suggesting that the development of tourism may mitigate air pollution. For example, Azam et al. [40] observed a negative effect of tourism on $\mathrm{CO}_{2}$ emissions in Thailand and Singapore, which was consistent with studies on EU countries [46,47] and Singapore [48]. A regional panel analysis in China showed that tourism has a negative impact on $\mathrm{CO}_{2}$ emissions in eastern China [49]. Ahmad et al. [2] further reported that the impact of tourism on environmental quality varies across different provinces. Specifically, a negative 
impact was found in the Ningxia, Qinghai, Gansu, and Shaanxi provinces, while a positive impact was found in Xinjiang.

In a nutshell, the literature shows that tourism and air pollution may have bilateral interactions. It is thus necessary to consider the potential endogeneity of air pollution when estimating its impact on the tourism industry.

\section{The Discontinuous Distribution of Air Pollution and Tourism in China}

This section demonstrates the discontinuous distribution of air pollution and tourism development around the north-south boundary of China. The relevant stylized facts will serve as a foundation for the further analyses in this paper.

\subsection{The Discontinuous Distribution of Air Pollution}

The line formed by Huai River and Qinling Mountains, at around latitude $33^{\circ} \mathrm{N}$, is the geographic boundary between northern and southern China. Due to budgetary limitations, since the planned economy period, the central government has implemented distinct policies for winter indoor heating in these two regions [16]. In most northern cities, the government subsidizes coal for winter indoor heating against the cold. This is called the "Huai River Policy". In contrast, in the south, this policy is not prevalent. Since the use of coals generates substantial emissions, the air quality in the northern cities is worse than that in the south, ceteris paribus. This phenomenon was already confirmed in the literature. For example, Almond et al. [16] showed that the degree of air pollution has a considerable leap from the south to the north side of the Huai River-Qinling Mountains. Chen et al. [50] and Ebenstein et al. [51] utilized this discontinuity to estimate the impact of air pollution on health. Huang and Lanz [52] used this to evaluate impacts on wage and house price.

Figure 1 demonstrates the discontinuous distribution of air pollution in 274 Chinese cities located at different degrees of latitude. We use the $\mathrm{PM}_{10}$ concentration as the indicator of air pollution. From the graph, we observe that the degree of air pollution has a strong relationship with the latitudes of the cities. In southern China, the air pollution increases along with the latitude. Around the north-south boundary, latitude $33^{\circ} \mathrm{N}$, annual average $\mathrm{PM}_{10}$ density has an apparent jump, from around $0.08 \mathrm{mg} / \mathrm{m}^{3}$ to nearly $0.1 \mathrm{mg} / \mathrm{m}^{3}$. This occurs as the result of the Huai River Policy. After this leap, air quality is stable for some degrees of latitude. Finally, when the latitude becomes larger and larger, the level of air pollution declines.

We also formally utilize a regression discontinuity design to test the effect of the Huai River Policy on $\mathrm{PM}_{10}$ density. (Th details about the data and sample are documented in Section 4) We use the following empirical model of a sharp RDD:

$$
\mathrm{PM} \mathrm{O}_{i}=\alpha_{0}+\alpha_{1} \text { North }_{i}+\eta F\left(\text { Latitude }_{i}\right)+v_{i}
$$

where $P M 10_{i}$ is the density of the $\mathrm{PM}_{10}$ concentration in city $i$; North $h_{i}$ is a dummy variable indicating whether the city is located in north China, and thus, covered by Huai River Policy $(=1$ if in the north, and $=0$ otherwise); Latitude $e_{i}$ is the degree of latitude; $v_{i}$ is the error term. Within the RDD framework, $P M 10_{i}$ is the outcome variable; and $F\left(\right.$ Latitude $\left._{i}\right)$ represents the polynomial terms of the running variable Latitude $_{i}$. We are interested in the average treatment effect (ATE) of the policy, which is measured by the coefficient $\alpha_{1}$. The model is estimated by a local polynomial regression. We first use a second-order polynomial, and allow different bandwidths at the two sides of the policy cutoff boundary, to obtain our baseline estimate. The point estimate, which confirms a statistically significant impact at the 10\% significance level, is shown in the first row of column (a) in Table 1 . The Huai River Policy raised $\mathrm{PM}_{10}$ by $0.018 \mathrm{mg} / \mathrm{m}^{3}$. To check the robustness, in column (b), we add the logarithm of GDP and population as additional covariates, and, in column (c), we use a third-order polynomial function and restrict using the same bandwidths on both sides of the policy boundary. Our finding holds. 


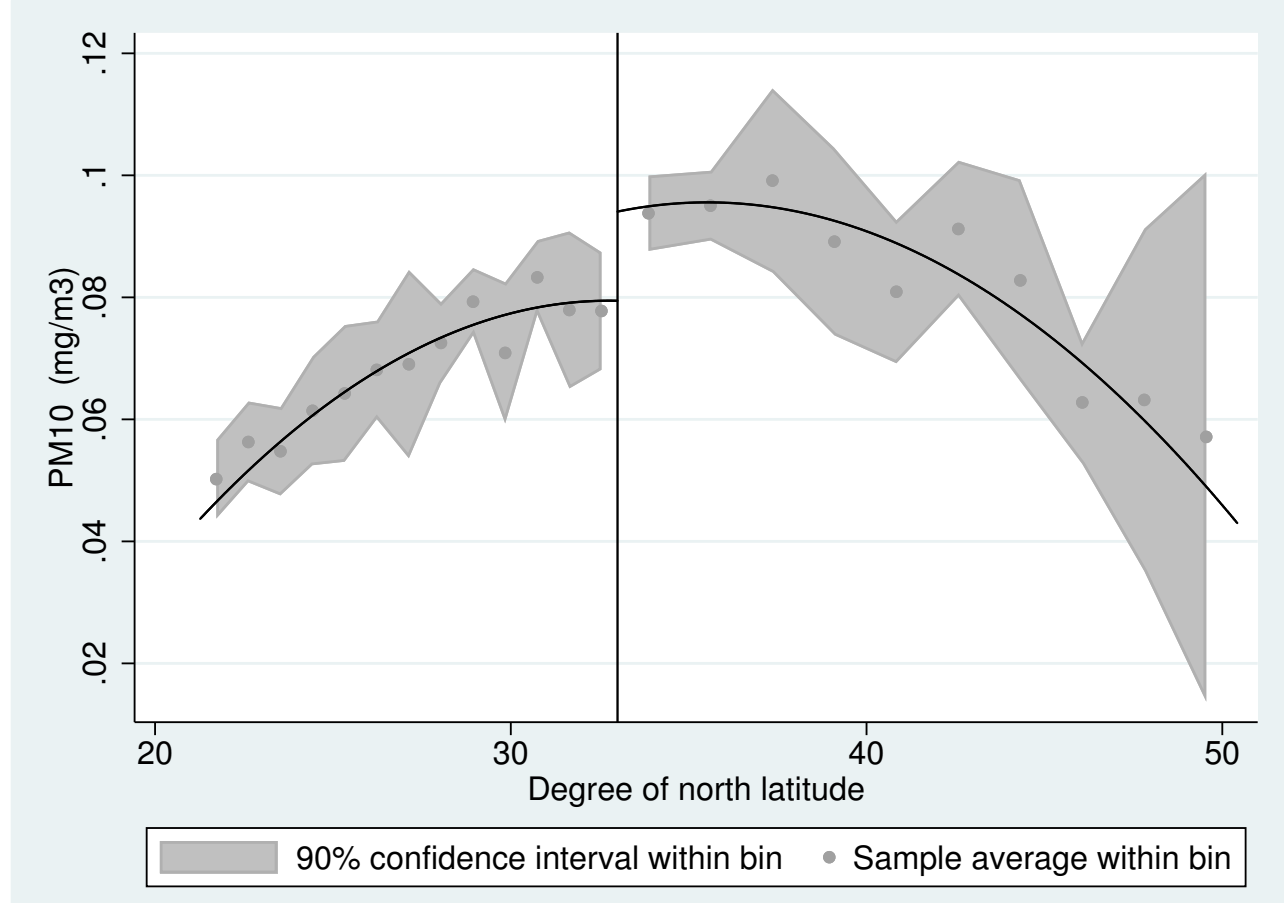

Figure 1. Annual average $\mathrm{PM}_{10}$ concentrations of Chinese cities in different latitudes. Note: The gray points represent the annual average $\mathrm{PM}_{10}$ concentrations across a set of cities grouped in bins according to the degrees of latitude. The gray shadowed area demonstrates the $90 \%$ confidence interval for each bin. The bins were constructed through a data-driven procedure based on the mean squared error (MSE)-optimal bandwidth selector. The vertical line in the middle of the figure indicates the position of latitude $33^{\circ} \mathrm{N}$. The plotted curves report the fitted values from a regression of $\mathrm{PM}_{10}$ concentration on a second-order polynomial in latitude, estimated separately on each side of the north-south boundary.

Table 1. Regression discontinuity estimates of the impacts of the Huai River Policy.

\begin{tabular}{lccc}
\hline Outcome Variable & (a) & $(\mathbf{b})$ & (c) \\
\hline$P M_{10}$ & $0.018^{*}$ & $0.012^{*}$ & $0.022^{*}$ \\
& $(0.011)$ & $(0.007)$ & $(0.013)$ \\
Tourism receipts & $-0.338^{* * *}$ & $-0.304^{* * *}$ & $-0.192^{*}$ \\
& $(0.128)$ & $(0.112)$ & $(0.098)$ \\
Tourist arrivals & $-3.968^{* *}$ & $-3.226^{*}$ & -1.963 \\
& $(1.695)$ & $(1.747)$ & $(1.361)$ \\
\hline Observations & 274 & 274 & 274 \\
Polynomial type & 2nd order & 2nd order & 3rd order \\
Same bandwidths in both sides & No & No & Yes \\
Additional covariates & No & Yes & No \\
\hline
\end{tabular}

Note: (1) Statistical significance: ${ }^{*} p<0.1{ }^{* *} p<0.05 ;{ }^{* * *} p<0.01$. Standard errors are in parentheses. (2) This table presents the regression discontinuity estimates of the impacts of the Huai River policy on three outcome variables: $\mathrm{PM}_{10}$ concentration $\left(\mathrm{mg} / \mathrm{m}^{3}\right)$, the ratio of inbound tourism receipts to local GDP (\%), and the ratio of inbound tourist arrivals to the local population (\%). (3) Column (a) gives the baseline result; column (b) adds the logarithm GDP and the population as additional covariates; column (c) uses a third-order polynomial function and restricts using the same bandwidths at both sides of the policy boundary.

\subsection{The Discontinuous Distribution of Tourism}

Now, we move to inspect the relationship between tourism and latitude. Figure 2 shows the distribution of receipts from inbound tourism as a ratio to local GDP. Similar to what we can read from Figure 1, this graph shows at least two important points. First, the tourism revenue has a strong relationship with latitude. Second, there is an obvious discontinuity around the latitude $33^{\circ} \mathrm{N}$. Particularly, the tourism receipts-to-GDP ratio suddenly drops when moving from the south to the 
north. This abrupt negative change of tourism revenue is in contrast to the sudden positive change of $\mathrm{PM}_{10}$ displayed in Figure 1. Thus, it is reasonable to conjecture that tourism revenue has a negative correlation with air pollution.

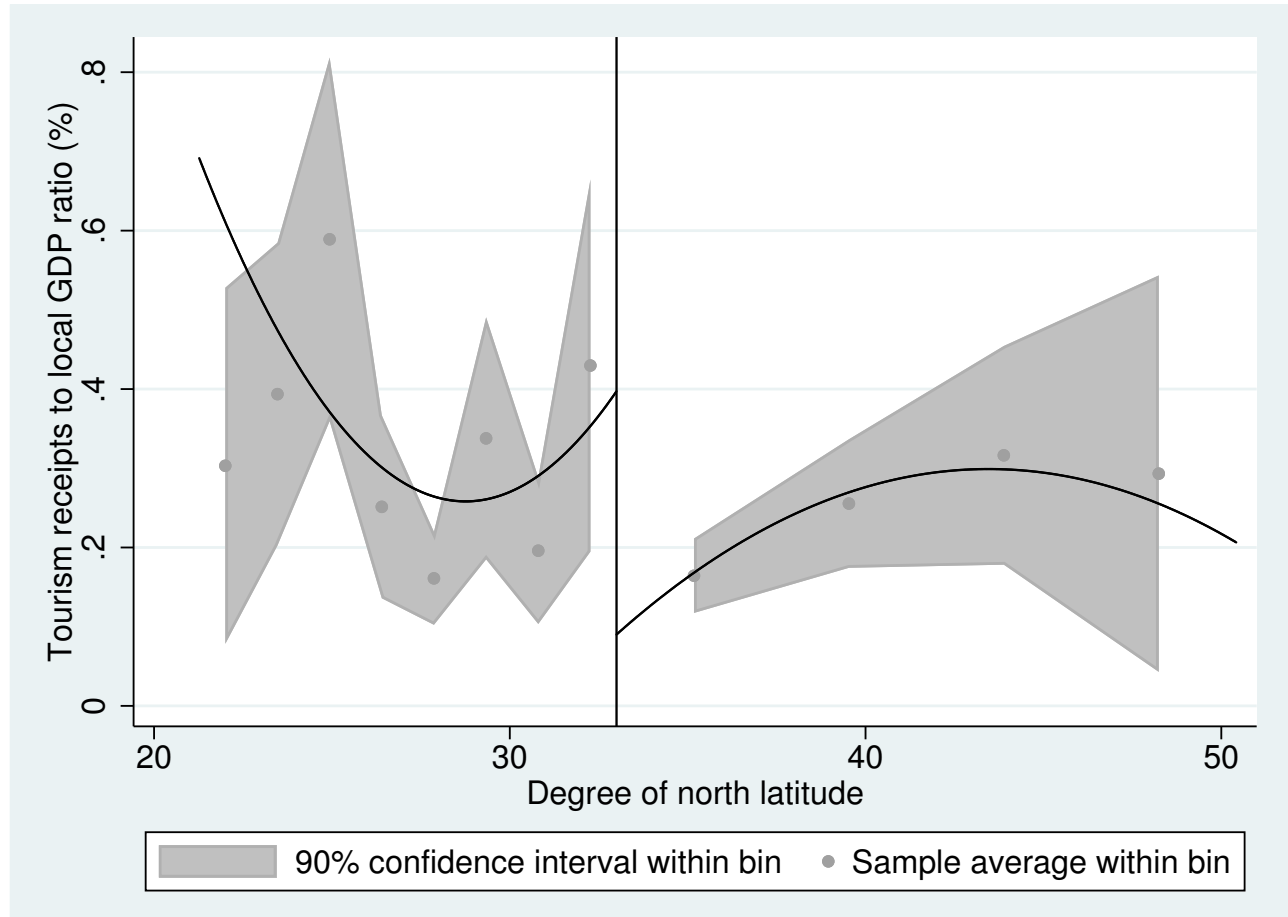

Figure 2. Annual average inbound tourism receipts-to-local GDP ratios of Chinese cities in different latitudes. Note: The gray points represent the annual average inbound tourism receipts-to-local GDP ratios across a set of cities grouped in bins according to the degrees of latitude. The gray shadowed area demonstrates the $90 \%$ confidence interval for each bin. The bins were constructed through a data-driven procedure based on the mean squared error (MSE)-optimal bandwidth selector. The vertical line in the middle of the figure indicates the position of latitude $33^{\circ} \mathrm{N}$. The plotted curves report the fitted values from a regression of the tourism receipts-to-local GDP ratio on a second-order polynomial in latitude, estimated separately on each side of the north-south boundary.

Figure 3 shows the relationship between the latitude and the ratio of inbound tourist arrivals to the local population. The distribution of the tourist arrivals-to-population ratio was similar to that of tourism revenue, as shown in Figure 2. It is especially notable that there is substantial discontinuity around the north-south boundary. Compared to the situation of $\mathrm{PM}_{10}$ demonstrated in Figure 1, we guess that tourist amount is negatively correlated with air pollution.

Besides the visual observation of the sudden drop of tourism around the north-south boundary, we also use a regression discontinuity design to examine the effects of the Huai River policy. The estimates rely on Equation (1), with the outcome variables of tourism receipts and tourist arrivals. As documented in the second and third rows of column (a) in Table 1, our baseline RD estimates show that Huai River Policy resulted in significant drops in tourism receipts and tourist arrivals at the $1 \%$ and $5 \%$ significance levels, respectively. The results are robust if we add additional covariates, or change the polynomial type and the bandwidth, as shown in columns (b) and (c) of Table 1. The finding that Huai River Policy had significant impacts on tourism generates a strong implication. Since this policy was designed only for winter-heating purpose, it has no direct link to tourism. Taking into account that we had already confirmed the crucial influence of the Huai River Policy on $\mathrm{PM}_{10}$ concentration, we can reasonably believe that the impact of the policy on tourism is through the channel of air pollution. 
This implies that a dummy variable, indicating whether a city is covered by the Huai River Policy, can work as the instrument variable for air pollution to help identify pollution's impacts on tourism.

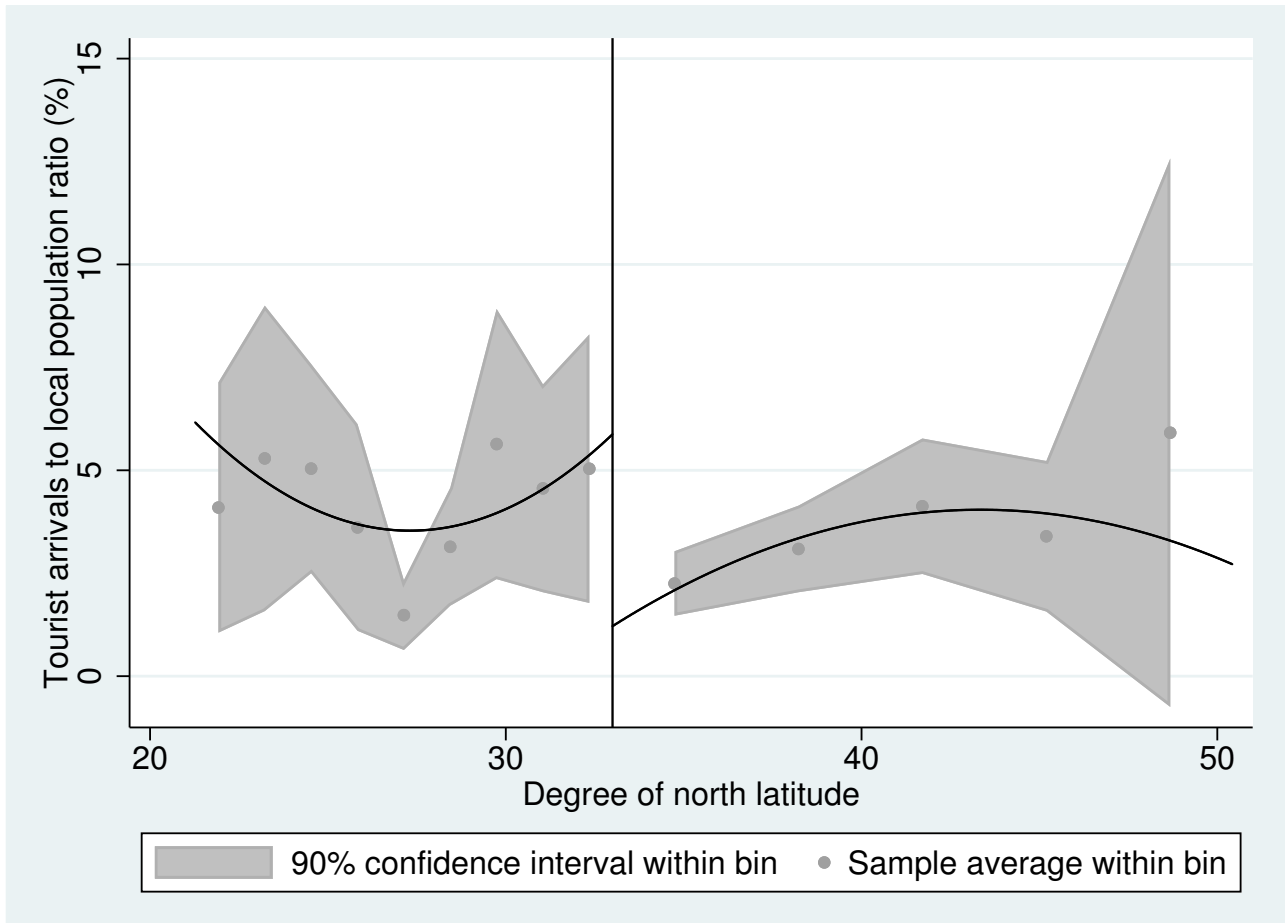

Figure 3. Annual average inbound tourist arrivals-to-local population ratios of Chinese cities in different latitudes. Note: The gray points represent the annual average inbound tourist arrivals-to-local population ratios across a set of cities grouped in bins according to the degrees of latitude. The gray shadowed area demonstrates the $90 \%$ confidence interval for each bin. The bins were constructed through a data-driven procedure based on the mean squared error (MSE)-optimal bandwidth selector. The vertical line in the middle of the figure indicates the position of latitude $33^{\circ} \mathrm{N}$. The plotted curves report the fitted values from a regression of tourist arrivals-to-local population ratio on a second-order polynomial in latitude, estimated separately on each side of the north-south boundary.

\section{Empirical Model and Data}

In this section, we explain the econometric model and the data used in our empirical analyses.

\subsection{Empirical Model}

In order to estimate the impact of air pollution on tourism development, a linear model is established as follows:

$$
\text { Tourism }_{i}=\beta_{0}+\beta_{1} P M 10_{i}+\theta^{\prime} X_{i}+\varepsilon_{i},
$$

where the dependent variable Tourism $_{i}$ is an indicator of tourism development in city $i$. We primarily consider Receipts $s_{i}$, the ratio of inbound tourism receipts to local GDP. We use this relative value of tourism revenue to GDP, rather than an absolute value of revenue volume because we want to measure the degree of tourism development in each city, rather than its scale. Besides the index of tourism revenue, later we will also investigate its extensive and intensive margins separately. The indicator for the extensive margin is Tourist ${ }_{i}$, which is the number of inbound tourist arrivals as a ratio to local population. The indicator for the intensive margin is Expenditure ${ }_{i}$, which is the average expenditure of each tourist. The core explanatory variable of interest in our analyses is the level of air pollution. We use $P M 10_{i}$, density of $\mathrm{PM}_{10}$ concentration, to measure air pollution. Ebenstein et al. [51] showed there was significant damage from $\mathrm{PM}_{10}$ concentrations in Chinese cities on the health of the residents. Furthermore, as one of the most important components of TSP (Total Suspended 
Particulates), $\mathrm{PM}_{10}$ substantially lowers the air visibility. Thus, $\mathrm{PM}_{10}$ is a crucial indicator for air pollution (In the robustness analysis section, we will additionally test the validity of our findings using another two indices: $A Q I_{i}$, the Air Quality Index; and $P M 2.5_{i}$, the density of $\left.\mathrm{PM}_{2.5}\right) . X_{i}$ is a vector of control variables including: the number of $5 \mathrm{~A}$ - and $4 \mathrm{~A}-$-rated scenic spots $\left(\right.$ Scenic $\left._{i}\right)$, the number of star-rated hotels $\left(\mathrm{Hotel}_{i}\right)$, the density of the transportation infrastructure (Transport $\left.{ }_{i}\right)$, industrial structure $\left(\right.$ Structure $\left._{i}\right)$, government size $\left(\right.$ GovSize $\left._{i}\right)$, and the GDP per capita $\left(G D P p c_{i}\right) \cdot \varepsilon_{i}$ represents the error term.

As discussed in the Introduction and Literature Review, air pollution is probably endogenous because tourism may have impacts on environmental quality. An estimate on the coefficient $\beta_{1}$ without dealing with endogeneity potentially introduces bias. To mitigate endogeneity, we use a 2SLS-IV (two-stage least squares-instrumental variable) approach based on the discontinuous distribution of air pollution and tourism in China, as already analyzed in Section 3. Previously, we have used RDD to confirm the significant impacts of the Huai River Policy on both pollution and tourism variables. Since the design purpose of the policy had nothing to do with the local tourism industry, the policy's impact on tourism should be indirect and works via some mediating variables. If the policy only influences tourism through its impacts on pollution, it is valid to treat Equation (1) as the first stage equation in a 2SLS regression. To simplify, we employ a parametric version of Equation (1). Specifically, in the 2SLS our first stage regression is:

$$
P M 10_{i}=\gamma_{0}+\gamma_{1} \text { North }_{i}+\gamma_{2} \text { Latitude }_{i}+\gamma_{3} \text { Latitude }_{i}^{2}+u_{i}
$$

where $\operatorname{North}_{i}$ is a dummy variable indicating whether the city is located in northern China $(=1$ if in the north, and $=0$ otherwise); Latitude $e_{i}$ is the degree of latitude; Latitude $e_{i}^{2}$ is the square of latitude; $u_{i}$ is error term. After Equation (3) is estimated, the fitted value of $\mathrm{PM}_{10}$ density is used to replace $P M 10_{i}$ in Equation (2). This constructs the second-stage regression. Similar 2SLS models, which utilize the nonlinear relationship between air pollution and latitude with the existence of the Huai River Policy, have been exploited in Chen et al. [50], Ebenstein et al. [51], and Huang and Lanz [52]. Chen et al. [50] and Ebenstein et al. [51] evaluated the impact of air pollution on health. Huang and Lanz [52] investigated its impacts on wage and house prices.

Table 2 gives detailed definitions of all the variables used in our regressions.

Table 2. List of variables used in the regressions.

\begin{tabular}{|c|c|}
\hline Variable & Definition \\
\hline \multicolumn{2}{|c|}{ Dependent variables } \\
\hline Receipts & Receipts from the inbound tourism industry, as a ratio to local GDP (\%) \\
\hline Tourist & Number of inbound tourist arrivals, as a ratio to the local population (\%) \\
\hline Expenditure & $\begin{array}{l}\text { Average expenditure of each inbound tourist ( } \$ 1000) \text {, equaling the total tourism receipts } \\
\text { divided by tourist arrivals }\end{array}$ \\
\hline \multicolumn{2}{|c|}{ Core explanatory variables of interest } \\
\hline PM10 & $\begin{array}{l}\left.\text { Density of } \mathrm{PM}_{10} \text { (particulate matter smaller than } 10 \mu \mathrm{m}\right) \text { concentration in the air } \\
\left(\mathrm{mg} / \mathrm{m}^{3}\right)\end{array}$ \\
\hline $\begin{array}{l}A Q I \text { (used for } \\
\text { robustness check) }\end{array}$ & $\begin{array}{l}\text { Air quality index, calculated according to the Technical Regulation on Ambient Air } \\
\text { Quality Index (HJ 633-2012) published by China's Ministry of Environmental Protection }\end{array}$ \\
\hline $\begin{array}{l}\text { PM2.5 (used for } \\
\text { robustness check) }\end{array}$ & $\begin{array}{l}\text { Density of } \mathrm{PM}_{2.5} \text { (particulate matter smaller than } 2.5 \mu \mathrm{m} \text { ) concentration in the air } \\
\left(\mathrm{mg} / \mathrm{m}^{3}\right)\end{array}$ \\
\hline
\end{tabular}


Table 2. Cont.

\begin{tabular}{ll}
\hline Variable & Definition \\
\hline Control variables & \\
\hline Scenic & $\begin{array}{l}\text { Number of 5A- and 4A-rated scenic spots, divided by the local population (since a } \\
\text { 5A-rated spot is usually considered to be much more attractive, one 5A spot is regarded } \\
\text { as equal to three 4A spots) }\end{array}$ \\
\hline Hotel & $\begin{array}{l}\text { Number of star-rated hotels, divided by the local population (we use the average value } \\
\text { during } 2000 \text { and 2003, to deal with the concern that the number of hotels in the current } \\
\text { period is affected by contemporary tourism development) }\end{array}$ \\
\hline Transport & Density of transportation infrastructure, proxied by the road length (km) per area (km ${ }^{2}$ ) \\
\hline Structure & $\begin{array}{l}\text { Industrial structure, proxied by the ratio of the service sector GDP to the industrial } \\
\text { sector GDP }\end{array}$ \\
\hline GovSize & Government size, measured by the ratio of fiscal spending to local GDP \\
\hline GDPpc & $\begin{array}{l}\text { Logarithm of GDP per capita (RMB, at the constant price in 2000) (we use the average } \\
\text { value during 2000 and 2003, to deal with the concern that the overall economic growth in } \\
\text { the current period is affected by contemporary tourism development) }\end{array}$ \\
\hline Variables for the first stage regression in 2SLS \\
\hline North & $\begin{array}{l}\text { Dummy variable indicating the city location (=1 if the city is located in north China, } \\
=0 \text { otherwise) }\end{array}$ \\
\hline Latitude & Latitude of the city center \\
\hline
\end{tabular}

\subsection{Data}

We collect data for approximately 300 prefecture-level administrative districts in China (For convenience, we will refer to "cities" as including these administrative districts). This initial sample is highly representative since it covers around $90 \%$ of the area of China. The sample period spans over four years, between 2009 and 2012. We use the annual average over these four years to avoid disturbances at the business cycle frequency. We extract the data of $\mathrm{PM}_{10}$ density from a series of yearly published reports- "The Report on the State of the Environment of China". The reports, written by China's Ministry of Environmental Protection (MEP), provide official data about the environmental quality in different areas of China. The reason why we choose the period 2009-2012 is that MEP released a relatively complete $\mathrm{PM}_{10}$ dataset, which covers approximately 300 cities in China, during this four-year period. In the robustness checks, we will also use the measures of $A Q I$ and $\mathrm{PM}_{2.5}$ concentration to inspect our findings. $A Q I$ is calculated according to the method in the MEP's Technical Regulation on Ambient Air Quality Index (HJ 633-2012), using the data of $\mathrm{PM}_{10}, \mathrm{SO}_{2}$, and $\mathrm{NO}_{2}$ documented in MEP's report series. The data of $\mathrm{PM}_{2.5}$ is from NASA's Global Annual $\mathrm{PM}_{2.5}$ Grids data $[53,54]$. (Here, we clarify several important points about the $A Q I$ and $\mathrm{PM}_{2.5}$ indictors. (1) Following Huang and Lanz [52], we use the data of $\mathrm{PM}_{10}, \mathrm{SO}_{2}$, and $\mathrm{NO}_{2}$ to calculate the value of $A Q I$. Strictly speaking, we should also take into account the values of $\mathrm{CO}, \mathrm{O}_{3}$ and $\mathrm{PM}_{2.5}$, according to the standard of the MEP's Technical Regulation on Ambient Air Quality Index (HJ 633-2012). However, the Report on the State of the Environment of China only presents the data for the former three pollutants. Because of this data availability issue, the latter three pollutants are not considered in our calculations. The detailed index construction method is discussed in HJ 633-2012 and Huang and Lanz [52]. (2) The data provided by MEP is based on direct measurements in different local observation stations. Thus, MEP's data can accurately reflect the degree of air pollution of each city. The $\mathrm{PM}_{2.5}$ data provided by NASA comes from the remote sensing measurement of space satellites. The measurement error is relatively larger, compared to the data from local observation stations. Thus, our baseline regressions utilize MEP's data, while NASA's data is used for robustness checks. (3) In our sample, the Pearson correlation coefficient between $A Q I$ and $\mathrm{PM}_{10}$ is 0.986 , and the correlation between $\mathrm{PM}_{2.5}$ and $\mathrm{PM}_{10}$ is 0.178 . Given our sample size, $A Q I$ and $\mathrm{PM}_{2.5}$ are both positively correlated 
with $\mathrm{PM}_{10}$ at the $1 \%$ statistical significance level. Our later robustness checks will also make it clear that our empirical findings hold no matter which air pollution index is used. In other words, we have no concerns about the selection of the pollution indicators because our analyses are not sensitive to that.) The latitude data is from NGCC, the National Geomatics Center of China. The variables of tourism and other control variables are from the China Statistical Yearbook for Regional Economy in the corresponding years.

There are several special cities within our sample. We regard them as outliers. For example, every year, a very large volume of travelers from Hong Kong and Macao visit Shenzhen and Zhuhai cities for the purposes of shopping, and visiting relatives or friends, as these cities are mutually adjacent. A similar phenomenon also occurs in some border cities. In Chinese inbound tourism statistics, those travelers who usually arrive and leave within one day are all recorded as inbound tourists. Obviously, those visitors are different from "inbound tourists" in a general sense, and, thus, should be cleaned out from our sample. To get rid of the outliers, we delete cities with values of Receipts ${ }_{i}$, Tourist ${ }_{i}$, or Expenditure $_{i}$ within the top $5 \%$ of the initial sample. Finally, we obtain a sample of 274 cities, covering over $80 \%$ of the area of China. Table 3 gives the summary statistics of the variables.

Table 3. Summary statistics.

\begin{tabular}{lcccc}
\hline Variable & Mean & SD & Min & Max \\
\hline Receipts & 0.281 & 0.369 & 0 & 1.814 \\
Tourist & 3.706 & 5.263 & 0.003 & 30.798 \\
Expenditure & 0.383 & 0.179 & 0.062 & 0.948 \\
\hline PM10 & 0.079 & 0.026 & 0.026 & 0.276 \\
AQI & 0.064 & 0.013 & 0.028 & 0.162 \\
PM2.5 & 0.034 & 0.016 & 0.003 & 0.073 \\
\hline Scenic & 4.396 & 4.199 & 0 & 25 \\
Hotel & 0.071 & 0.067 & 0.005 & 0.412 \\
Transport & 0.912 & 0.484 & 0.029 & 2.054 \\
Structure & 0.761 & 0.347 & 0.125 & 2.692 \\
GovSize & 0.199 & 0.146 & 0.048 & 1.112 \\
GDPpc & 8.797 & 0.613 & 7.329 & 10.721 \\
\hline North & 0.496 & 0.501 & 0 & 1 \\
Latitude & 33.433 & 6.757 & 21.27 & 50.42 \\
\hline
\end{tabular}

\section{Results}

In this section, we report our estimation results. Section 5.1 discusses the estimated impact of air pollution on inbound tourism receipts. Section 5.2 discusses the impact on tourist arrivals. In Section 5.3, we evaluate the effect on expenditure per tourist. We find that air pollution significantly reduces tourism revenue and tourist amount, but it positively correlates with the expenditure per tourist. Our estimates indicate that the deprivation of air quality has different effects on the extensive and intensive margins of tourism: pollution incurs some potential tourists to give up travel plans, but it raises the expenditure of tourists who ultimately arrive at China. The overall effect of air pollution on Chinese inbound tourism development is detrimental.

\subsection{The Impact of Air Pollution on Tourism Receipts}

In order to evaluate air pollution's impact on tourism revenue, the inbound tourism receipts-tolocal GDP ratio (Receipts $s_{i}$ ) works as the dependent variable in Equation (2). For the purpose of comparison, we first report the OLS estimate in column (a) of Table 4. The result shows a significant negative effect of $\mathrm{PM}_{10}$ concentration on tourism revenue. Regarding the control variables, we find that the amount of scenic spots $\left(\right.$ Scenic $\left._{i}\right)$, amount of hotels $\left(\right.$ Hotel $\left._{i}\right)$, road density (Transport $\left.{ }_{i}\right)$, and the relative size of the service sector $\left(\right.$ Structure $_{i}$ ) all have significant positive correlations with tourism receipts. The estimated coefficients of these control variables are consistent with previous literature. 
In addition, we detect a positive correlation between the government size (GovSize $_{i}$ ) and the tourism revenue, probably because Chinese local governments play crucial roles in the economic development and the transformation of industrial structure. The coefficient of GDP per capita (GDPpc $c_{i}$ ) is positive, but not statistically significant.

Since air pollution is possibly endogenous, the OLS estimate reported in column (a) may have considerable bias. In order to mitigate the endogeneity, we now exploit the 2SLS-IV approach. The estimates and the associated test statistics from 2SLS are displayed in column (b) of Table 4. The Durbin $\chi^{2}$ statistic and the $\mathrm{Wu}-\mathrm{Hausman} F$ statistic are 7.005 and 6.952, respectively. These two statistics are both significant at the $1 \%$ level, rejecting the null hypothesis that $\mathrm{PM}_{10}$ is exogenous. This endorses the necessity for using the IV approach to mitigate endogeneity. The Hansen $J$ statistic is 0.742 , which does not reject the joint null hypothesis that our instruments are valid instruments, i.e., uncorrelated with the error term, and that the excluded instruments from the estimated equation are correctly excluded. This indicates that our selection of instrument variables is suitable. The estimated coefficient shows that, after controlling for the endogeneity, air pollution indeed significantly reduces inbound tourism receipts. It is especially notable that the coefficient of $\mathrm{PM}_{10}$ in column (b) is -4.477 . Its magnitude is substantially larger than that of -1.408 , the estimated coefficient in column (a). This makes it clear that, if we fail to consider endogeneity, air pollution's damage on China's inbound tourism would be significantly underestimated.

Our finding is not only statistically significant, but also economically significant. According to our 2SLS estimate, if $\mathrm{PM}_{10}$ density increases by $0.1 \mathrm{mg} / \mathrm{m}^{3}$, the tourism receipts-to-local GDP ratio will decline by 0.45 percentage points. In our sample, the average GDP of the cities is around 126 billion $\mathrm{RMB}$, and a decline of 0.45 percentage points means a reduction of 567 million RMB (approximately 80 million USD). This is a huge loss.

Table 4. Impact of air pollution on tourism receipts.

\begin{tabular}{|c|c|c|c|c|c|c|}
\hline \multirow{3}{*}{ Variable } & \multirow[b]{2}{*}{ OLS } & \multirow[b]{2}{*}{ IV } & \multicolumn{4}{|c|}{ Robustness Check } \\
\hline & & & $\begin{array}{l}\text { IV } \\
\text { (LIML) }\end{array}$ & $\begin{array}{l}\text { IV } \\
\text { (GMM) }\end{array}$ & $\begin{array}{l}\text { IV } \\
\text { (Use AQI) }\end{array}$ & $\begin{array}{l}\text { IV } \\
\text { (Use } \mathrm{PM}_{2.5} \text { ) }\end{array}$ \\
\hline & (a) & (b) & (c) & (d) & (e) & (f) \\
\hline PM10 & $-1.408^{*}$ & $-4.477^{* *}$ & $-4.504^{* *}$ & $-3.995^{* *}$ & & \\
\hline$A Q I$ & & & & & $-8.556^{* *}$ & \\
\hline PM 2.5 & & & & & & $-29.686^{* *}$ \\
\hline Scenic & $0.019 * * *$ & $0.019^{* * *}$ & $0.019 * * *$ & $0.020^{* * *}$ & $0.019^{* * *}$ & $0.024^{* * *}$ \\
\hline Hotel & $2.089 * * *$ & $1.826^{* * *}$ & $1.823^{* * *}$ & $1.845^{* * *}$ & $1.795^{* * *}$ & 0.713 \\
\hline Transport & $0.091 *$ & $0.114^{* *}$ & $0.114 * *$ & $0.116^{* *}$ & $0.107^{* *}$ & $0.780 * *$ \\
\hline Structure & $0.160 * *$ & $0.219^{* * *}$ & $0.220 * * *$ & $0.208^{* * *}$ & $0.220 * * *$ & $0.154 *$ \\
\hline GovSize & $0.560 * *$ & $0.635^{* *}$ & $0.635^{* *}$ & $0.641^{* *}$ & $0.599 * *$ & 0.314 \\
\hline$G D P p c$ & 0.061 & 0.105 & 0.105 & 0.104 & 0.102 & 0.121 \\
\hline Constant & -0.691 & -0.899 & -0.901 & $-0.932 *$ & -0.668 & -0.832 \\
\hline Observations & 274 & 274 & 274 & 274 & 274 & 274 \\
\hline Adj- $R^{2}$ & 0.322 & 0.28 & 0.28 & 0.292 & 0.283 & -0.194 \\
\hline Durbin $\chi^{2}$ stat. & - & $7.005^{* * *}$ & - & - & $7.116^{* * *}$ & $8.566^{* * *}$ \\
\hline Wu-Hausman $F$ stat. & - & $6.952^{* * *}$ & - & - & $7.006^{* * *}$ & $8.552 * * *$ \\
\hline Hansen $J$ stat. & - & 0.742 & 0.741 & 0.742 & 0.486 & 0.601 \\
\hline
\end{tabular}

Statistical significance: ${ }^{*} p<0.1 ;{ }^{* *} p<0.05 ;{ }^{* * *} p<0.01$.

To validate our finding, we conduct several robustness checks for our 2SLS estimate. In columns (c) and (d), we report the results using LIML-IV (Limited Information Maximum Likelihood-IV) and GMM-IV (Generalized Method of Moments-IV), respectively. We find that the coefficients demonstrated in column (b) do not have large changes. In other words, our results are reliable. Furthermore, we address the concern that $\mathrm{PM}_{10}$ is perhaps not the most crucial indicator for air pollution, when the tourists make their decisions. We reestimate Equation (2) by using another two 
indices of air pollution. In column (e), we use $A Q I$; in column (f), we use $\mathrm{PM}_{2.5}$ concentration. Our previous finding still holds: air pollution significantly decreases tourism revenue.

The variation of tourism receipts may be caused by variations in two dimensions: the extensive margin, namely, the number of tourists; and the intensive margin, namely, the average expenditure of each traveler. In the next two subsections, we analyze these two margins.

\subsection{The Impact of Air Pollution on Tourist Arrivals}

Now, we investigate the impact of air pollution on the number of inbound travelers. We use the ratio of inbound tourist arrivals to the local population (Tourist ${ }_{i}$ ) as the dependent variable, to estimate Equation (2). The estimate results in Table 5 show a significant negative effect of air pollution on the tourist amount. The coefficient of $\mathrm{PM}_{10}$ reported in column (b) indicates that the tourist arrivals-to-local population ratio will reduce by 4.6 percentage points, if the $\mathrm{PM}_{10}$ density rises by $0.1 \mathrm{mg} / \mathrm{m}^{3}$. Among our sample cities, the average population is 4.1 million. Thus, a decline of 4.6 percentage points means a reduction of 0.19 million tourists. In columns (c)-(f), we demonstrate the results of the robustness checks. Clearly, we have a robust finding: air pollution incurs many potential tourists to give up their plans to visit China.

If we incorrectly ignore the endogeneity of air pollution, the damage would be substantially underestimated. Column (a) displays the result of the OLS estimate, which only reports a value of -20.776 for the coefficient of $\mathrm{PM}_{10}$. This value is less than half of -46.066 , the estimated coefficient by the 2SLS-IV approach documented in column (b).

Table 5. Impact of air pollution on tourist arrivals.

\begin{tabular}{|c|c|c|c|c|c|c|}
\hline \multirow{3}{*}{ Variable } & \multirow[b]{2}{*}{ OLS } & \multirow[b]{2}{*}{ IV } & \multicolumn{4}{|c|}{ Robustness check } \\
\hline & & & $\begin{array}{l}\text { IV } \\
\text { (LIML) }\end{array}$ & $\begin{array}{l}\text { IV } \\
\text { (GMM) }\end{array}$ & $\begin{array}{l}\text { IV } \\
\text { (Use AQI) }\end{array}$ & $\begin{array}{l}\text { IV } \\
\text { (Use PM } \text { PM.5 })\end{array}$ \\
\hline & (a) & (b) & (c) & (d) & (e) & (f) \\
\hline PM10 & $-20.776^{* * *}$ & $-46.066^{*}$ & $-46.094 *$ & $-44.488^{* *}$ & & \\
\hline$A Q I$ & & & & & $-86.828 *$ & \\
\hline$P M 2.5$ & & & & & & $-302.464 *$ \\
\hline Scenic & $0.278^{* * *}$ & $0.280^{* * *}$ & $0.280 * * *$ & $0.277^{* * *}$ & $0.280^{* * *}$ & $0.328^{* * *}$ \\
\hline Hotel & $35.860 * * *$ & $33.688^{* * *}$ & $33.686^{* * *}$ & $33.822 * * *$ & $33.434 * * *$ & $22.388^{*}$ \\
\hline Transport & $1.713^{* *}$ & $1.895^{* * *}$ & $1.895^{* * *}$ & $1.960^{* * *}$ & $1.821^{* * *}$ & 8.680 * \\
\hline Structure & $1.694^{* *}$ & $2.180 * *$ & $2.181^{* *}$ & $2.161^{* *}$ & $2.172 * *$ & 1.503 * \\
\hline GovSize & $4.179^{* *}$ & $4.800 * *$ & $4.800 * *$ & $4.806^{* *}$ & $4.424 * *$ & 1.522 \\
\hline$G D P p c$ & $2.013 * *$ & $2.378^{* *}$ & $2.378^{* *}$ & $2.358^{* *}$ & $2.343^{* *}$ & $2.539 * *$ \\
\hline Constant & $-19.809^{* * *}$ & $-21.526^{* * *}$ & $-21.528^{* * *}$ & $-21.530 * * *$ & $-19.137^{* *}$ & $-20.809 * *$ \\
\hline Observations & 274 & 274 & 274 & 274 & 274 & 274 \\
\hline Adj- $R^{2}$ & 0.493 & 0.479 & 0.479 & 0.481 & 0.476 & 0.227 \\
\hline Durbin $\chi^{2}$ stat. & - & $3.132 *$ & - & - & 3.535 * & $5.742 * *$ \\
\hline Wu-Hausman $F$ stat. & - & $3.064 *$ & - & - & $3.464 *$ & $5.672 * *$ \\
\hline Hansen $J$ stat. & - & 0.047 & 0.047 & 0.047 & 0.05 & 0.254 \\
\hline
\end{tabular}

Statistical significance: ${ }^{*} p<0.1 ;{ }^{* *} p<0.05 ;{ }^{* * *} p<0.01$.

\subsection{The Impact of Air Pollution on Expenditure per Tourist}

In this subsection, we consider whether air pollution affects the expenditure of a typical tourist. The average expenditure of each tourist (Expenditure ${ }_{i}$ ) is used as dependent variable in Equation (2). Previously, when we estimated the influence of air pollution on tourism receipts (Receipts $s_{i}$ ) and tourist amount (Tourist ${ }_{i}$ ), we used the instrumental variables regarding the discontinuous distribution of $\mathrm{PM}_{10}$ to mitigate endogeneity. This time, however, when we regress Expenditure ${ }_{i}$ on $P M 10_{i}$, we find that the statistic tests do not reject the null hypothesis of exogeneity. This enables us to use OLS directly. Our estimates are reported in Table 6. Our results show a strong positive correlation 
between pollution and tourism expenditure per capita. According to the coefficient in column (a), if the $\mathrm{PM}_{10}$ concentration rises by $0.1 \mathrm{mg} / \mathrm{m}^{3}$, the average expenditure per tourist will expand by 77.1 USD. The positive impact of air pollution on tourism expenditure does not necessarily imply that the tourists are willing to consume more in cities with more severe pollution. Instead, the reason is plausibly unpleasant: for example, air pollution may encumber the transportation system such that tourists need to increase transportation costs; additionally, tourists may have additional health care expenses because pollution increases the health risk. Therefore, in the long term, the positive impact of air pollution on tourism expenditure probably hurts the development of tourism by lowering tourists' experiences and the reputations of travel destinations. In columns (b) and (c), we make estimations by using $A Q I$ and $\mathrm{PM}_{2.5}$ as dependent variables, respectively. The results confirm the finding in column (a). Among the control variables, the hotel amount $\left(\right.$ Hotel $\left._{i}\right)$ has a significant negative correlation to tourism expenditure, perhaps because a larger number of hotels indicates strong competition and lower average prices in the hotel industry; the coefficient of the relative share of service sector (Structure $e_{i}$ ) is significantly positive, as tourists' expenditure is majorly aimed towards the consumption on services, and not of industrial products; local GDP per capita $\left(G D P p c_{i}\right)$ has a significant positive coefficient, since the price level is usually higher in a city with a higher GDP per capita. The estimated coefficients of other control variables, Scenic ${ }_{i}$, Transport ${ }_{i}$, GovSize $_{i}$, are not statistically significant.

Our empirical analyses have found that air pollution reduces tourist arrivals, but it increases the average expenditure per tourist. The relative importances of these two effects determine the net effect of air pollution on tourism receipts. We can illustrate this via a simple example. Considering an "average" city with the initial Tourist ${ }_{i}$ value being at its mean level, 0.03706 , and Expenditure $_{i}$ being at its mean level, $383 \mathrm{USD}$, if $\mathrm{PM}_{10}$ increases by $0.01 \mathrm{mg} / \mathrm{m}^{3}$, according to the estimated coefficients in column (b) of Tables 5 and 6, Tourist $t_{i}$ will decline by 0.0046 - a reduction of $12.4 \%$, and Expenditure $e_{i}$ will rise by 7.71 USD—an increase of $2 \%$. Obviously, the relative magnitude of air pollution's negative impact on tourist arrivals exceeds that of pollution's positive impact on the tourism expenditure per capita. In consequence, the aggregate effect of pollution on tourism revenue is negative.

Table 6. Impact of air pollution on expenditure per tourist.

\begin{tabular}{|c|c|c|c|}
\hline \multirow{3}{*}{ Variable } & \multirow[b]{2}{*}{ OLS } & \multicolumn{2}{|c|}{ Robustness Check } \\
\hline & & $\begin{array}{l}\text { OLS } \\
\text { (Use AQI) }\end{array}$ & $\begin{array}{l}\text { OLS } \\
\text { (Use } \mathrm{PM}_{2.5} \text { ) }\end{array}$ \\
\hline & (a) & (b) & (c) \\
\hline PM10 & $0.771^{*}$ & & \\
\hline$A Q I$ & & $1.579 * *$ & \\
\hline PM2.5 & & & $2.100 *$ \\
\hline Scenic & 0.003 & 0.003 & 0.003 \\
\hline Hotel & $-0.453^{* *}$ & $-0.443^{* *}$ & $-0.413^{* *}$ \\
\hline Transport & 0.005 & 0.006 & -0.038 \\
\hline Structure & $0.063 *$ & $0.062 *$ & $0.076^{* *}$ \\
\hline GovSize & 0.08 & 0.085 & 0.114 \\
\hline$G D P p c$ & $0.159^{* * *}$ & $0.158^{* * *}$ & $0.164^{* * *}$ \\
\hline Constant & $-1.125^{* * *}$ & $-1.164^{* * *}$ & $-1.160 * * *$ \\
\hline Observations & 274 & 274 & 274 \\
\hline Adj- $R^{2}$ & 0.243 & 0.244 & 0.245 \\
\hline
\end{tabular}

\section{Discussion}

This study quantifies the influence of air pollution on the Chinese inbound tourism industry. It is found that air pollution significantly reduces tourism revenue and the number of international tourist arrivals, which is qualitatively consistent with the previous study results such as Deng et al. [34], Zhou et al. [36], Xu and Reed [38]. Some potential tourists might give up their travel 
plans to China when they are aware of China's haze problem. It is suggested that tourism policy makers should roll out more environmental policies for tackling air pollution in China. In addition, they should make more efforts to promote tourism and culture in China worldwide to overcome travelers' fear of air pollution. In addition, due to the fact that air pollution is closely related to climate change on a global scale $[55,56]$, air pollution in China could be a potential consequence of global climate change issue. Therefore, the findings of this study tend to raise public awareness of climate change and call for more sustainable tourism practices to preserve a healthy environment.

While the findings in this study emphasize the importance of good air quality for sustainable tourism, which is claimed by the existing literature, this study provides quantitatively novel insights. This study provides supplementary inputs to the view of Holden [57] that the tourism-environment relationship should be understood as being reciprocal. It is noted that air quality and tourism development have simultaneous impacts on each other. The existence of this bilateral causality results in the endogeneity of the regressor, which impedes a precise estimate for the impact of air pollution on tourism. If we fail to control for this issue, the impact may be either underestimated or overestimated. In this article, we take advantage of the quasi-experiment derived by the coal-based winter indoor heating policy in northern Chinese cities, to use the regression discontinuity design to quantify the influence of air pollution on Chinese inbound tourism. By analyzing data from 274 Chinese cities during the period of 2009-2012, it is found that an increase of $\mathrm{PM}_{10}$ by $0.1 \mathrm{mg} / \mathrm{m}^{3}$ will cause a decline of the tourism receipts-to-local GDP ratio by 0.45 percentage points, and a shrinkage of the tourist arrivals-to-local population ratio by 4.6 percentage points. Failing to consider the endogeneity results in substantial underestimates: the OLS estimates merely report a reduction of 0.14 percentage points in tourism receipts, and 2.1 percentage points in tourism arrivals, respectively.

Additionally, it is interesting to find that air pollution increases the international tourists' average expenditure, which has not been reported in prior studies. The potential reason for this might be that tourists who ultimately make their decision to visit China are likely to have longer trips because haze impedes transportation. Based on retail therapy, it is also possible that travelers tend to make purchases to lessen their negative emotions (e.g., depression, anxiety) that are evoked by the severe haze-fog [58].

\section{Conclusions, Limitations and Future Research}

In conclusion, the overall effect of air pollution on Chinese inbound tourism development is detrimental. This study highlights the importance of good air quality for sustainable tourism, and demonstrates that the magnitude of regression coefficients is plausibly much larger than what has been estimated before.

Like any other studies, this study is bound by certain limitations. First, this study does not capture the air pollution trends in the most recent years, since the $\mathrm{PM}_{10}$ data for a wide set of Chinese cities released so far only covers the period from 2009 to 2012. The work could be improved if more data becomes available in the future. Second, while this study focuses on air pollution, it should be considered that other types of pollution (e.g., water pollution, noise pollution) might also affect tourism. If the alternative types of pollution could be measured precisely at the city level, a comprehensive evaluation on the impact of pollution on tourism would be promising.

Future research may explore the mechanisms underlying the relationship between air pollution and tourism expenditure at the micro-level. In light of the study of Wang et al. [29], who examined the effect of air pollution in the place of origin on outbound tourism demand by utilizing transaction data from a leading online travel agent (OTA) in China, it is also interesting to verify their results by using the data derived from MEP. Additionally, future studies could examine the role of China's air pollution control policies in the relationship between environment and tourism industry. The insights of this study can also be extended to assess the circumstances in other countries, especially those densely populated developing countries like India, Indonesia and Pakistan. 
Author Contributions: Conceptualization and Funding Acquisition, D.D. and X.X.; Methodology, Data Curation, Formal Analysis, and Original Draft Preparation, D.D.; Literature Review, and Review and Editing, X.X.; Software, Validation, and Supervision, Y.F.W.

Funding: This research was funded by the Fundamental Research Funds for the Central Universities (Grant Nos. JBK1801039 and JBK1809054).

Acknowledgments: The authors are grateful to the editors and three anonymous referees for their comments and suggestions.

Conflicts of Interest: The authors declare no conflict of interest.

\section{References}

1. Liu, Z. Sustainable Tourism Development: A Critique. J. Sustain. Tour. 2003, 11, 459-475. [CrossRef]

2. Ahmad, F.; Draz, U.M.; Su, L.; Ozturk, I.; Rauf, A. Tourism and Environmental Pollution: Evidence from the One Belt One Road Provinces of Western China. Sustainability 2018, 10, 3520. [CrossRef]

3. Mutinda, R.; Mayaka, M. Application of destination choice model: Factors influencing domestic tourists destination choice among residents of Nairobi, Kenya. Tour. Manag. 2012, 33, 1593-1597. [CrossRef]

4. Zhang, A.; Zhong, L.; Xu, Y.; Wang, H.; Dang, L. Tourists' Perception of Haze Pollution and the Potential Impacts on Travel: Reshaping the Features of Tourism Seasonality in Beijing, China. Sustainability 2015, 7, 2397-2414. [CrossRef]

5. Becken, S.; Wilson, J. The impacts of weather on tourist travel. Tour. Geogr. 2013, 15, 620-639. [CrossRef]

6. Kirillova, K.; Fu, X.; Lehto, X.; Cai, L. What makes a destination beautiful? Dimensions of tourist aesthetic judgment. Tour. Manag. 2014, 42, 282-293. [CrossRef]

7. World Health Organization. Ambient Air Pollution: Health Impacts. 2019. Available online: https: / /www.who.int/airpollution/ambient/health-impacts/en/ (accessed on 1 March 2019).

8. Melamed, M.L.; Schmale, J.; von Schneidemesser, E. Sustainable policy-Key considerations for air quality and climate change. Curr. Opin. Environ. Sustain. 2016, 23, 85-91. [CrossRef]

9. AirVisual. World Most Polluted Cities $2018\left(\mathrm{PM}_{2.5}\right)$. 2019. Available online: https://www.airvisual.com/ world-most-polluted-cities (accessed on 1 March 2019).

10. Reuters. India's Polluted Air Claimed 1.24 Million Lives in 2017: Study. 2018. Available online: https:/ / www.reuters.com/article/us-india-pollution-lancet/indias-polluted-air-claimed-1-24-m illion-lives-in-2017-study-idUSKBN1O51T8 (accessed on 1 March 2019).

11. Parklin, B. Toxic Smog Threatens to Suffocate India's Tourism Industry. Financial Times, 18 January 2019.

12. Khan, M.Z. The Growing Problem of Air Pollution in Pakistan. 2017. Available online: https://thewire.in/e nvironment/growing-problem-pollution-pakistan (accessed on 1 March 2019).

13. Li, M.; Zhang, L. Haze in China: Current and future challenges. Environ. Pollut. 2014, 189, 85-86. [CrossRef]

14. Wall Street Journal. Pollution Halves Visitors to Beijing. 2013. Available online: https://blogs.wsj.com/chin arealtime/2013/10/31/beijing-air-pollution-drives-50-drop-in-visitors/ (accessed on 1 March 2019).

15. Cheng, S. Inbound Tourism Still Rising. 2018. Available online: http://www.chinadaily.com.cn/a/201805 /23/WS5b04bdc4a3103f6866ee9ff2.html (accessed on 1 March 2019).

16. Almond, D.; Chen, Y.; Greenstone, M.; Li, H. Winter Heating or Clean Air? Unintended Impacts of China's Huai River Policy. Am. Econ. Rev. 2009, 99, 184-190. [CrossRef]

17. Lee, C.C.; Chang, C.P. Tourism development and economic growth: A closer look at panels. Tour. Manag. 2008, 29, 180-192. [CrossRef]

18. Oh, C.O. The contribution of tourism development to economic growth in the Korean economy. Tour. Manag. 2005, 26, 39-44. [CrossRef]

19. Akama, J.S.; Kieti, D. Tourism and Socio-economic Development in Developing Countries: A Case Study of Mombasa Resort in Kenya. J. Sustain. Tour. 2007, 15, 735-748. [CrossRef]

20. Durbarry, R. Tourism and Economic Growth: The Case of Mauritius. Tour. Econ. 2004, 10, $389-401$. [CrossRef]

21. Gössling, S.; Hall, C.M. Uncertainties in Predicting Tourist Flows Under Scenarios of Climate Change. Clim. Chang. 2006, 79, 163-173. [CrossRef]

22. Kavallinis, I.; Pizam, A. The Environmental Impacts of Tourism-Whose Responsibility Is It Anyway? The Case Study of Mykonos. J. Travel Res. 1994, 33, 26-32. [CrossRef] 
23. Kuo, N.W.; Chen, P.H. Quantifying energy use, carbon dioxide emission, and other environmental loads from island tourism based on a life cycle assessment approach. J. Clean. Prod. 2009, 17, 1324-1330. [CrossRef]

24. Saenz-de Miera, O.; Rosselló, J. Modeling tourism impacts on air pollution: The case study of PM10 in Mallorca. Tour. Manag. 2014, 40, 273-281. [CrossRef]

25. Eckhardt, S.; Hermansen, O.; Grythe, H.; Fiebig, M.; Stebel, K.; Cassiani, M.; Baecklund, A.; Stohl, A. The influence of cruise ship emissions on air pollution in Svalbard-A harbinger of a more polluted Arctic? Atmos. Chem. Phys. 2013, 13, 8401-8409. [CrossRef]

26. Fraj, E.; Matute, J.; Melero, I. Environmental strategies and organizational competitiveness in the hotel industry: The role of learning and innovation as determinants of environmental success. Tour. Manag. 2015, 46, 30-42. [CrossRef]

27. Lenzen, M.; Sun, Y.Y.; Faturay, F.; Ting, Y.P.; Geschke, A.; Malik, A. The carbon footprint of global tourism. Nat. Clim. Chang. 2018, 8, 522-528. [CrossRef]

28. Sajjad, F.; Noreen, U.; Zaman, K. Climate change and air pollution jointly creating nightmare for tourism industry. Environ. Sci. Pollut. Res. 2014, 21, 12403-12418. [CrossRef] [PubMed]

29. Wang, L.; Fang, B.; Law, R. Effect of air quality in the place of origin on outbound tourism demand: Disposable income as a moderator. Tour. Manag. 2018, 68, 152-161. [CrossRef]

30. Anaman, K.A.; Looi, C.N. Economic Impact of Haze-Related Air Pollution on the Tourism Industry in Brunei Darussalam. Econ. Anal. Policy 2000, 30, 133-143. [CrossRef]

31. BBC News. China Pollution: First Ever Red Alert in Effect in Beijing. 2015. Available online: https: / / www.bbc.com/news/world-asia-china-35026363 (accessed on 1 March 2019).

32. Becken, S.; Jin, X.; Zhang, C.; Gao, J. Urban air pollution in China: destination image and risk perceptions. J. Sustain. Tour. 2017, 25, 130-147. [CrossRef]

33. Peng, J.; Xiao, H. How does smog influence domestic tourism in China? A case study of Beijing. Asia Pac. J. Tour. Res. 2018, 23, 1115-1128. [CrossRef]

34. Deng, T.; Li, X.; Ma, M. Evaluating impact of air pollution on China's inbound tourism industry: A spatial econometric approach. Asia Pac. J. Tour. Res. 2017, 22, 771-780. [CrossRef]

35. Xu, X.; Reed, M. Perceived pollution and inbound tourism in China. Tour. Manag. Perspect. 2017, 21, $109-112$. [CrossRef]

36. Zhou, B.; Qu, H.; Du, X.; Yang, B.; Liu, F. Air Quality and Inbound Tourism in China. Tour. Anal. 2018, 23, 159-164. [CrossRef]

37. Chen, C.M.; Lin, Y.L.; Hsu, C.L. Does air pollution drive away tourists? A case study of the Sun Moon Lake National Scenic Area, Taiwan. Transp. Res. Part D Transp. Environ. 2017, 53, 398-402. [CrossRef]

38. Xu, X.; Reed, M. Perceived pollution and inbound tourism for Shanghai: A panel VAR approach. Curr. Issues Tour. 2019, 22, 601-614. [CrossRef]

39. Belsoy, J.; Korir, J.; Yego, J. Environmental Impacts of Tourism in Protected Areas. J. Environ. Earth Sci. 2012, 2, 64-73.

40. Azam, M.; Alam, M.M.; Hafeez, M.H. Effect of tourism on environmental pollution: Further evidence from Malaysia, Singapore and Thailand. J. Clean. Prod. 2018, 190, 330-338. [CrossRef]

41. Katircioğlu, S.T. International tourism, energy consumption, and environmental pollution: The case of Turkey. Renew. Sustain. Energy Rev. 2014, 36, 180-187. [CrossRef]

42. Katircioğlu, S.T.; Feridun, M.; Kilinc, C. Estimating tourism-induced energy consumption and $\mathrm{CO}_{2}$ emissions: The case of Cyprus. Renew. Sustain. Energy Rev. 2014, 29, 634-640. [CrossRef]

43. Wang, M.C.; Wang, C.S. Tourism, the environment, and energy policies. Tour. Econ. 2018, 24, 821-838. [CrossRef]

44. Lu, C.; Pang, M.; Yang, J.; Wang, D. Research on Interactions between the Economy and Environment in Tourism Development: Case of Qingyang, China. Sustainability 2018, 10, 4033. [CrossRef]

45. Tian, H.; Gao, J.; Hao, J.; Lu, L.; Zhu, C.; Qiu, P. Atmospheric pollution problems and control proposals associated with solid waste management in China: A review. J. Hazard. Mater. 2013, 252-253, 142-154. [CrossRef]

46. Dogan, E.; Aslan, A. Exploring the relationship among $\mathrm{CO}_{2}$ emissions, real GDP, energy consumption and tourism in the EU and candidate countries: Evidence from panel models robust to heterogeneity and cross-sectional dependence. Renew. Sustain. Energy Rev. 2017, 77, 239-245. [CrossRef] 
47. Lee, J.W.; Brahmasrene, T. Investigating the influence of tourism on economic growth and carbon emissions: Evidence from panel analysis of the European Union. Tour. Manag. 2013, 38, 69-76. [CrossRef]

48. Katircioğlu, S.T. Testing the tourism-induced EKC hypothesis: The case of Singapore. Econ. Model. 2014, 41, 383-391. [CrossRef]

49. Zhang, L.; Gao, J. Exploring the effects of international tourism on China's economic growth, energy consumption and environmental pollution: Evidence from a regional panel analysis. Renew. Sustain. Energy Rev. 2016, 53, 225-234. [CrossRef]

50. Chen, Y.; Ebenstein, A.; Greenstone, M.; Li, H. Evidence on the impact of sustained exposure to air pollution on life expectancy from China's Huai River policy. Proc. Natl. Acad. Sci. USA 2013, 110, 12936-12941. [CrossRef] [PubMed]

51. Ebenstein, A.; Fan, M.; Greenstone, M.; He, G.; Zhou, M. New evidence on the impact of sustained exposure to air pollution on life expectancy from China's Huai River Policy. Proc. Natl. Acad. Sci. USA 2017, 114, 10384-10389. [CrossRef]

52. Huang, X.; Lanz, B. The Value of Air Quality in Chinese Cities: Evidence from Labor and Property Market Outcomes. Environ. Resour. Econ. 2018, 71, 849-874. [CrossRef]

53. Van Donkelaar, A.; Martin, R.V.; Brauer, M.; Hsu, N.C.; Kahn, R.A.; Levy, R.C.; Lyapustin, A.; Sayer, A.M.; Winker, D.M. Global Estimates of Fine Particulate Matter Using a Combined Geophysical-Statistical Method with Information from Satellites. Environ. Sci. Technol. 2016, 50, 3762-3772. [CrossRef] [PubMed]

54. Van Donkelaar, A.; Martin, R.V.; Brauer, M.; Hsu, N.C.; Kahn, R.A.; Levy, R.C.; Lyapustin, A.; Sayer, A.M.; Winker, D.M. Global Annual PM 2.5 Grids from MODIS, MISR and SeaWiFS Aerosol Optical Depth (AOD) with GWR, 1998-2016; Columbia University: New York, NY, USA, 2018; doi:10.7927/H4ZK5DQS.

55. Gössling, S. Global environmental consequences of tourism. Glob. Environ. Chang. 2002, 12, $283-302$. [CrossRef]

56. Scott, D.; Gössling, S.; Hall, C.M. International tourism and climate change. Wiley Interdiscip. Rev. Clim. Chang. 2012, 3, 213-232. [CrossRef]

57. Holden, A. The environment-tourism nexus: Influence of market ethics. Ann. Tour. Res. 2009, 36, 373-389. [CrossRef]

58. Wu, L.; Yang, F. Influence of Haze-Fog on Consumers' Desire for Money. Open J. Soc. Sci. 2019, 7, $190-208$. [CrossRef] 